\title{
OTR12 Concepção de indicadores de desempenho por processos do Departamento de Controle de Qualidade em aderência aos objetivos estratégicos de Bio-Manguinhos
}

\author{
Cristine Maria de Lima Andrade ${ }^{1}$, André Ribeiro de Oliveira² \\ ${ }^{1}$ Bio-Manguinhos, Fiocruz, Rio de Janeiro, RJ \\ 2 Universidade Federal do Rio de Janeiro - UFRJ
}

Introdução: A concepção de indicadores de desempenho que apóiem efetivamente a tomada de decisão nas organizações é uma etapa crítica nos projetos de sistema de medição de desempenho. Utilizandose os processos do Departamento de Controle de Qualidade (DEQUA) de Bio-Manguinhos e aplicando-se a metodologia do Balanced Scorecard (BSC) aos objetivos estratégicos previamente definidos da organização, alinharam-se os indicadores da área em busca de melhores resultados.

Objetivo: Definir indicadores de desempenho a partir dos macroprocessos, aplicável diretamente ao Departamento de Qualidade (DEQUA), por método qualitativo que seja reprodutível às demais áreas estratégicas em aderência ao Mapa Estratégico de BioManguinhos 2010-2020.

Metodologia: Primeiramente realizaram-se entrevistas com os gestores ou substitutos das seções, definindo-se os focos principais das suas atividades, isto é, os seus macroprocessos, entradas e saídas, em um programa Power Point. Em seguida, definiu-se os atributos de desempenho (tempo, flexibilidade, confiabilidade e prontidão), relativos a cada processo e agrupados em níveis superiores (laboratórios e divisões), verificando a coesão, coerência e importância para validação, em planilha Excel. Por meio de entrevistas com a Gerente do Departamento e a Vice-Diretora de Qualidade, foi possível revisar os macroprocessos o nível estratégico, definindo-se os indicadores de maior aderência ao Mapa Estratégico 2010-2020 da unidade. Por fim, mapeados os indicadores do Departamento, estes foram submetidos à Assessoria de Planejamento de Bio-Manguinhos para avaliação.

Resultados: Foram selecionados para o DEQUA sete importantes indicadores de desempenho: a) índice percentual de retestes; b) atendimento a novas demandas e exigências; c) satisfação ao cliente (interno); d) prazo para fechamento de certificados de análise de produtos, e) estudos de estabilidade finalizados por categorias, f) atendimento ao SAC; g) capacidade de atendimento e demanda no prazo. Estes indicadores têm alinhamento com os seguintes objetivos definidos pela organização no Mapa Estratégico, nas perspectivas: 1) Auto sustentabilidade - Eficácia na utilização dos recursos; 2) Sociedade - Atendimento das demandas de saúde, Satisfação dos 
Clientes, Atendimento das demandas de saúde pública, Fortalecimento da Imagem Institucional Pública; 3) Processos - Lançamento de novos produtos e serviços; 4) Aprendizado e Crescimento com os objetivos Motivação dos funcionários, Excelência Gerencial, Retenção de pessoas, Qualificação de funcionários, Eficiência na comunicação, definidos para a perspectiva de aprendizado e crescimento. Estes resultados deixam claro que a teoria de Balanced Scorecard com as relações de causa e efeito para alinhamento da estratégia com os vetores entre os objetivos, facilitará a posição desejada de acordo com a Estratégia pretendida de Bio-Manguinhos.

Conclusão: A introdução dos Conceitos de BalancedScorecard, Macroprocessos e Indicadores de Desempenho aos Gestores do Departamento de Qualidade, proporcionou o estabelecimento de indicadores de desempenho de cunho participativo e alinhados à estratégia definida por Bio-Manguinhos. A definição dos indicadores de desempenho por processos pode ocasionar, com a sua implantação, o acompanhamento e a melhoria no gerenciamento do macroprocesso bem como o fortalecimento do negócio no mercado competitivo atual.

Palavras-Chave: Indicadores de Desempenho, Balanced Scorecard, Alinhamento, Estratégia 